\title{
Anti-inflammatory activity of 3- cinnamoyltribuloside and its metabolomic analysis in LPS-activated RAW 264.7 cells
}

\author{
Zhennan Wang ${ }^{1,2 \dagger}$, Ying Guan ${ }^{3 \dagger}$, Rui Yang ${ }^{1}$, Junjian Li ${ }^{2}$, Junsong Wang ${ }^{1}$ and Ai-Qun Jia ${ }^{1,2^{*}}$ (D)
}

\begin{abstract}
Background: Inflammation is a response to tissue injuries, which is indispensable and important for human health, but excessive inflammation can potentially cause damage to the host organisms. Camellia nitidissima Chi, one traditional medicinal and edible plant in China, was reported to exhibit anti-inflammation capability. Hence, this study was conducted to isolate the bioactive compounds from the flowers of $C$. nitidissima Chi and evaluate their anti-inflammatory activity.

Methods: The phytochemicals from the flowers of C. nitidissima Chi were isolated and purified by silica gel, Sephadex LH-20 gel, C18 reversed silica gel, semi-preparative HPLC, and identified by the spectrum technologies. The anti-inflammatory activity of isolated compounds was evaluated using cultured macrophage RAW 264.7 cells. Whereafter the potential metabolic mechanism of the anti-inflammatory activity of the bioactive compound was investigated by a ${ }^{1} \mathrm{H}$-NMR based metabolomics approach. The metabolites in ${ }^{1} \mathrm{H}$-NMR spectra were identified by querying the Human Metabolome Database and Madison Metabolomics Consortium Database online. And the multivariate statistical analysis was performed to evaluate the variability of metabolites among samples and between sample classes.
\end{abstract}

Results: The compound isolated from the flowers of C. nitidissima Chi was identified as 3-cinnamoyltribuloside (3CT). 3-CT could inhibit the NO production and the mRNA expression of iNOS involved in lipopolysaccharide (LPS)activated RAW 264.7 cells. Moreover, 3-CT could inhibit the expression of a series of inflammatory cytokines, including TNF- $a, I L-1 \beta$, and IL-6, both at the mRNA level and protein level. The ${ }^{1} H-N M R$ based metabolomics approach was applied to investigate the potential metabolic mechanism of the anti-inflammatory activity of 3-CT. Thirty-five metabolites were identified and assigned. Orthogonal signal correction partial least-squares discriminant analysis (OSC-PLS-DA) of the ${ }^{1} \mathrm{H}-\mathrm{NMR}$ data showed 3-CT could balance the significant changes in many endogenous metabolites (e.g., choline, glucose, phenylalanine) induced by LPS in RAW 264.7 cells, which related to cholinergic anti-inflammatory pathway, oxidative stress, energy metabolism, and amino acids metabolism.

(Continued on next page)

\footnotetext{
* Correspondence: jiaaiqun@gmail.com

†Zhennan Wang and Ying Guan contributed equally to this work.

${ }^{1}$ School of Environmental and Biological Engineering, Nanjing University of

Science and Technology, Nanjing 210094, China

${ }^{2}$ School of Life and Pharmaceutical Sciences, Key Laboratory of Tropical

Biological Resources of Ministry Education, Hainan University, Haikou 570228,

China

Full list of author information is available at the end of the article
}

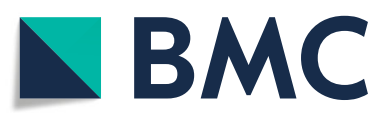

(ㄷ) The Author(s). 2020 Open Access This article is licensed under a Creative Commons Attribution 4.0 International License, which permits use, sharing, adaptation, distribution and reproduction in any medium or format, as long as you give appropriate credit to the original author(s) and the source, provide a link to the Creative Commons licence, and indicate if changes were made. The images or other third party material in this article are included in the article's Creative Commons licence, unless indicated otherwise in a credit line to the material. If material is not included in the article's Creative Commons licence and your intended use is not permitted by statutory regulation or exceeds the permitted use, you will need to obtain permission directly from the copyright holder. To view a copy of this licence, visit http://creativecommons.org/licenses/by/4.0/ The Creative Commons Public Domain Dedication waiver (http://creativecommons.org/publicdomain/zero/1.0/) applies to the data made available in this article, unless otherwise stated in a credit line to the data. 
(Continued from previous page)

Conclusion: 3-CT, isolated from the flowers of C. nitidissima Chi, had potent anti-inflammatory activity in LPS-activated RAW 264.7 cells. Furthermore, our results indicated that 3-CT had effects on the cholinergic anti-inflammatory pathway, oxidative stress, energy metabolism, and amino acids metabolism in LPS-activated RAW 264.7 cells.

Keywords: 3-cinnamoyltribuloside, Anti-inflammatory, Cholinergic anti-inflammatory pathway, Metabolomics, RAW 264.7

\section{Background}

Inflammation is part of the complex and essential biological process responding to tissue mechanical injuries, biological stimuli, or due to aberrant autoimmune response [1, 2]. Although inflammation is indispensable and important for homeostasis and human health, excessive inflammation can potentially cause damage for the host organisms and induce many diseases, such as cancer, rheumatoid arthritis, diabetes, septic shock, and cardiovascular diseases due to the toxic effects of several inflammatory factors [1, 3]. Macrophages, which have two distinguishable phenotypes, classical/pro-inflammatory (M1) and alternative/anti-inflammatory (M2), play an important role in the immune responses to infection in the inflammatory process $[4,5]$. Lipopolysaccharide (LPS), one of the outer cell membrane components of gram-negative bacteria, is a famous endotoxin which can activate macrophages to produce many kinds of inflammatory cytokines such as tumor necrosis factor- $\alpha$ (TNF$\alpha$ ), interleukin-1 $\beta$ (IL-1 $\beta$ ), and interleukin-6 (IL-6) etc. $[6,7]$. Besides, LPS can also activate macrophages to produce inflammatory mediators, like nitric oxide (NO) $[1,7]$. Therefore, the inhibition of LPS activated macrophages to release cytokines and mediators is always used to develop and evaluate new anti-inflammatory agents.

In recent years, drug development has often relied on the use of natural and synthetic drugs for the prevention or treatment of many diseases [8]. Compared with synthetic drugs, natural anti-inflammatory ingredients attract more and more attention due to their weak side effects [1, 9]. Currently, many natural ingredients have been put into clinical use as anti-inflammatory drugs, such as triptolide, resveratrol, silymarin [10, 11]. The medicinal and edible plants in China are rich in antiinflammatory components, especially flavonoids that have the activity of multiple anti-inflammatory [12, 13]. Flavonoids are usually via interfering with nuclear factor kappa $\mathrm{B}(\mathrm{NF} \mathrm{K})$ and mitogen-activated protein kinase (MAPK) to control inflammatory signaling cascades and inhibit the formation of inflammatory cytokines, such as TNF- $\alpha$, IL-1 $\beta$, and IL-6 [14-16].

Camellia nitidissima Chi, distributed in Southern China and Northern Vietnam, is one traditional medicinal and edible plant in China. Our previous researches showed that the $C$. nitidissima Chi flowers had high total phenolic content, and played a potential role in human health, especially $C$. nitidissima Chi flowers could inhibit the formation of advanced glycation endproducts [17], showed the anti-quorum sensing [18] and antioxidant [19] activities. Besides, C. nitidissima Chi was also reported to exhibit anti-inflammation capability [20]. However, it is not known if the flowers of $C$. nitidissima Chi, the rarest part of the species, have antiinflammatory activity, and if so, what anti-inflammatory compound(s) contribute(s) to such an activity.

3-cinnamoyltribuloside (3-CT), a rich source of cinnamolyglycoflavonoid, possess a broad range of biological activities, including antioxidant, antimycobacterial, and cytotoxicity [21-23]. In this study, 3-CT isolated from the flowers of $C$. nitidissima Chi firstly, which showed potent anti-inflammatory activity in LPS-activated RAW 264.7 cells under bioassays. Furthermore, we evaluated the anti-inflammatory metabolic mechanism via ${ }^{1} \mathrm{H}$ NMR-based metabolomics after 3-CT treatment.

\section{Methods \\ Chemicals and reagents}

Lipopolysaccharides, (3-4,5-dimethylthiazol-2-yl)-2,5diphenyl tetrazolium bromide (MTT), dimethyl sulfoxide (DMSO), and sodium 3-(trimethylsilyl)-propionic acid (TSP) were purchased from Sigma (St. Louis, MO, USA). Dulbecco's modified eagle medium (DMEM), fetal bovine serum (FBS), and penicillin/ streptomycin were obtained from GIBCO (Grand Island, NY, USA). Trypsin was purchased from Solarbio science and technology co., Ltd. (Beijing, China). The nitric oxide assay kit was obtained from Nanjing Jiancheng Bioengineering Institute (Nanjing, China). Mouse tumor necrosis factor-alpha, interleukin $1 \beta$, and interleukin 6 ELISA kit were purchased from Multi Sciences biotechnology Co., Lid. (Hangzhou, China). Trizol Reagent was purchased from Invitrogen (Carlsbad, CA, USA). Acetonitrile (analytical grade) was purchased from Merck (Darmstadt, Germany). Deuterium oxide $\left(\mathrm{D}_{2} \mathrm{O}, 99.9 \%\right)$ was purchased from Sea Sky Bio Technology Co., Ltd. (Beijing, China). Other chemical reagents were purchased from Nanjing Shuangling Chemical Reagent Co., Ltd. (Nanjing, China).

\section{The isolation and purification of 3-CT from ethyl acetate fraction}

C. nitidissima Chi flowers were collected in July 2016 from a planting base in Fangchenggang, China. Then the 
ethyl acetate fraction of extracts from $C$. nitidissima Chi flowers was obtained following our previous study [19].

Next, the ethyl acetate fraction was repeatedly subjected to different column chromatographies, such as silica gel (200-300 meshes, Qingdao Marine Chemical Inc.), Sephadex LH-20 (GE Healthcare Bio-Sciences AB, Uppsala, Sweden), and $\mathrm{C}_{18}$ reversed silica gel (YMC, Japan), to yield 3 -CT $(83 \mathrm{mg})$. And ${ }^{1} \mathrm{H}$ - and ${ }^{13} \mathrm{C}-\mathrm{NMR}$ spectra were recorded on a Bruker AV-500 (Bruker Inc., Germany). ESI-MS was conducted on Thermo TSQ Quantum LC/MS spectrometers (USA).

\section{Cell culture}

A murine macrophage cell line RAW 264.7 was a kind gift from Dr. Yuan Xu from Nanjing University of Chinese Medicine (Nanjing, China). Cells were grown in high-glucose DMEM supplemented with 10\% FBS, and $1 \%$ antibiotics (penicillin and streptomycin) in a humidified incubator flushed continuously at $37^{\circ} \mathrm{C}$ with $5 \%$ $\mathrm{CO}_{2}$. The culture medium was refreshed every day.

\section{MTT assay for RAW 264.7cell cytotoxicity}

MTT assay was conducted as published methods [24], with some modifications. Firstly, 3-CT was dissolved in DMSO, and then diluted into different concentrations with the culture medium. The final DMSO concentration in all assays did not exceed $0.1 \%(\mathrm{v} / \mathrm{v})$. Cells were seeded in a 96 well plate at a density of $5 \times 10^{3}$ cells/well. After $24 \mathrm{~h}$, the cells were treated with various concentrations of 3-CT for $24 \mathrm{~h}$, and the final concentrations of 3CT were $0.625,1.25,2.5,5,10,20$, and $40 \mu \mathrm{M}$. DMSO (final concentration of $0.1 \%(\mathrm{v} / \mathrm{v}))$ served as a negative control, and cells without treatment served as the blank control. After $24 \mathrm{~h}$ treatment, cells were incubated with $5 \mathrm{mg} / \mathrm{mL}$ MTT solution for $4 \mathrm{~h}$ at $37^{\circ} \mathrm{C}$ and $5 \% \mathrm{CO}_{2}$. Then the medium was removed, and $150 \mu \mathrm{L}$ DMSO was added to dissolve the precipitation. Absorbance at 490 $\mathrm{nm}$ was determined using an ELISA reader (TECAN Infinite 200 Pro, Switzerland).

\section{Nitric oxide assay}

Production of NO by LPS-activated RAW 264.7 cells was measured by using the NO assay kit (Nanjing Jiancheng Bioengineering Institute). RAW 264.7 cells were incubated at $5 \times 10^{3}$ cells/well in 96 well-plates for $24 \mathrm{~h}$ at $37^{\circ} \mathrm{C}$ and $5 \% \mathrm{CO}_{2}$. And then the cells were treated with various concentrations of 3-CT in the presence of LPS $(1 \mu \mathrm{g} / \mathrm{mL})$. The final concentrations of 3 -CT were $0.3125,0.625,1.25,2.5,5$, and $10 \mu \mathrm{M}$. The cells without treatment served as the blank control. The cells with LPS + DMSO (final concentration of $0.1 \%(\mathrm{v} / \mathrm{v})$ ) in the absence of 3-CT served as the negative control (LPS group). After $24 \mathrm{~h}$ treatment, $\mathrm{NO}$ was analyzed following the manufacturer's protocols.

\section{Quantitative real-time PCR analysis}

The quantitative real-time PCR procedures were performed according to previous studies [4], with some modifications. RAW 264.7 cells were seeded into 6 wellplates for $24 \mathrm{~h}$ at $37^{\circ} \mathrm{C}$ and $5 \% \mathrm{CO}_{2}$. And then the cells were treated with various concentrations $(0.625,1.25$, $2.5,5$, and $10 \mu \mathrm{M})$ of $3-\mathrm{CT}$ in the presence of LPS $(1 \mu \mathrm{g} /$ $\mathrm{mL})$. The cells without treatment served as the blank control. The cells with LPS + DMSO (final concentration of $0.1 \%(\mathrm{v} / \mathrm{v}))$ in the absence of 3-CT served as the negative control (LPS group). After $24 \mathrm{~h}$ treatment, the total RNA was extracted with Trizol Reagent according to the manufacturer's recommended procedure. The RNA was then reverse transcribed into complementary DNA (cDNA) using commercial reverse transcript enzyme (KeyGene, Nanjing, China) according to the manufacturer's instructions. The real-time RT-PCR was performed in a $20 \mu \mathrm{L}$ volume using an SYBR Green PCR Core Reagent Kit (Vazyme, China) according to the manufacturer's instructions by Applied Biosystems 7300 RT-PCR System (USA). The relative expression of each gene was calculated by the $2^{-\Delta \Delta C T}$ method normalized to Gapdh. Forward and reverse primers used for this study are listed in Table 1.

\section{Measurements of TNF- $\alpha$, IL- $1 \beta$, IL- 6 by ELISA}

TNF- $\alpha$, IL-1 $\beta$, and IL- 6 produced by LPS-activated RAW 264.7 cells were determined by using mouse TNF$\alpha$, IL-1 $\beta$, and IL-6 ELISA kit, respectively. RAW 264.7 cells were incubated at $5 \times 10^{3}$ cells/well in 96 wellplates for $24 \mathrm{~h}$ at $37^{\circ} \mathrm{C}$ and $5 \% \mathrm{CO}_{2}$. And then the cells were treated with various concentrations $(0.3125,0.625$, $1.25,2.5,5$, and $10 \mu \mathrm{M})$ of $3-\mathrm{CT}$ in the presence of LPS $(1 \mu \mathrm{g} / \mathrm{mL})$. The cells without treatment served as the blank control. The cells with LPS + DMSO (final

Table 1 The sequences of primers used for quantitative real-time PCR

\begin{tabular}{|c|c|c|}
\hline Gene & Sense $\left(5^{\prime}-3^{\prime}\right)$ & Anti-sense $\left(5^{\prime}-3^{\prime}\right)$ \\
\hline $\mathrm{IL}-1 \beta$ & TGGAAAAGCGGTTTGTCTTC & TACCAGTTGGGGAACTCTGC \\
\hline IL-6 & GAGGATACCACTCCCAACAGACC & AAGTGCATCATCGTTGTTCATACA \\
\hline iNOS & CAGGAGGAGAGAGATCCGATTTA & GCATTAGCATGGAAGCAAAGA \\
\hline TNF-a & CATCTTCTCAAAATTCGAGTGAC & TGGGAGTAGACAAGGTACAACCC \\
\hline GAPDH & GGCCTTCCGTGTTCCTAC & TGTCATCATATCTGGCAGGTT \\
\hline
\end{tabular}


concentration of $0.1 \%(\mathrm{v} / \mathrm{v}))$ in the absence of $3-\mathrm{CT}$ served as the negative control (LPS group). After $24 \mathrm{~h}$ treatment, TNF- $\alpha$, IL-1 $\beta$, and IL- 6 were analyzed following the manufacturer's protocols.

\section{Metabolite extraction of LPS-activated RAW 264.7 cells}

Metabolites of LPS-activated RAW 264.7 cells were extracted according to the previous study [25], with some modifications. RAW 264.7 cells were incubated 100 -mm-diameter culture dish for $24 \mathrm{~h}$ at $37^{\circ} \mathrm{C}$ and $5 \%$ $\mathrm{CO}_{2}$, one dish as one sample for ${ }^{1} \mathrm{H}-\mathrm{NMR}$ analysis. And then three 3-CT treated groups were conducted at the concentrations of $2.5,5$, and $10 \mu \mathrm{M}$ corresponding to the low, medium, and high dosages in the presence of LPS $(1 \mu \mathrm{g} / \mathrm{mL})$. The cells without treatment served as the blank control. The cells with LPS + DMSO (final concentration of $0.1 \%(\mathrm{v} / \mathrm{v}))$ in the absence of $3-\mathrm{CT}$ served as the negative control (LPS group).

After $24 \mathrm{~h}$ treatment, the cells were washed with PBS three times. Then, the cells were scraped off in ice-cold solution of acetonitrile/water (1:1, v/v, $2 \mathrm{ml}$ per dish). Subsequently, from the obtained cell suspension, the intracellular metabolites were extracted through ultrasonication for $20 \mathrm{~min}$. Then, the mixtures were centrifuged at $12,000 \mathrm{rpm}$ and at $4{ }^{\circ} \mathrm{C}$ for $15 \mathrm{~min}$. Next, the supernatant was frozen at $-80^{\circ} \mathrm{C}$ overnight and then lyophilized in a freeze drier.

\section{${ }^{1} \mathrm{H}$-NMR measurements of extracts from LPS-activated RAW 264.7 cells}

The lyophilized extracts were rehydrated in $600 \mu \mathrm{L}$ of 99.8\% $\mathrm{D}_{2} \mathrm{O}$ phosphate buffer ( $\left.\mathrm{pH} 7.4\right)$, which contained $0.05 \%(\mathrm{w} / \mathrm{v})$ TSP. The mixture solutions were vortexed and centrifuged to eliminate the precipitates. Then the afforded transparent supernatants were shifted into NMR tubes for ${ }^{1} \mathrm{H}$-NMR analysis.

The ${ }^{1} \mathrm{H}-\mathrm{NMR}$ spectra of samples were acquired on a Bruker AVANCE III $500 \mathrm{MHz}$ NMR spectrometer, using the Carr-Purcell-Meiboom-Gill sequence [90( $\tau-180-\tau) n-$ acquisition] with a total spin-echo delay (2nt) of $40 \mathrm{~ms}$ to suppress the signals of proteins. The following parameters: controlling temperature of $298 \mathrm{~K}$, the spectral width of $10,000 \mathrm{~Hz}$, data points of $32 \mathrm{~K}$. The $\mathrm{D}_{2} \mathrm{O}$ provided a lock signal and the TSP was used as the chemical shift reference $\left({ }^{1} \mathrm{H}, 0.00 \mathrm{ppm}\right)$. The free induction decays were weighted using an exponential window function corresponding to a line-broadening of $0.5 \mathrm{~Hz}$ before a Fourier transformation.

\section{${ }^{1} \mathrm{H}$-NMR data processing and analysis of metabolites from LPS-activated RAW 264.7 cells}

Before analysis, the ${ }^{1} \mathrm{H}$-NMR spectra were phase- and baseline- corrected manually and referenced to the chemical shift of TSP ( $\delta$ 0.0 ppm) using Topspin 3.0 software (version 3.0, Bruker GmbH, Karlsruhe, Germany). Subsequently, all the spectra were exported to ASCII files using MestReNova (Version 8.0.1, Mestrelab Research SL) and then read into R software (https://www. r-project.org/) for multivariate analysis. Each spectrum was divided into $0.005 \mathrm{ppm}$ wide segments between 0.2 and $10 \mathrm{ppm}$. The segments between 4.3 and $5.8 \mathrm{ppm}$ were cut off to exclude the residual signal of water. All spectra were then normalized and mean-centered prior to multivariate statistical analysis.

The metabolites in ${ }^{1} \mathrm{H}$-NMR spectra were identified by querying the Human Metabolome Database (HMDB, http://www.hmdb.ca) and Madison Metabolomics Consortium Database (MMCD, http://mmcd.nmrfam.wisc.edu) online, aided by the Chenomx NMR suite 7.5 (Chenomx Inc., Edmonton, Canada) and further confirmed by statistical total correlation spectroscopy (STOCSY) [26].

Multivariate statistical analysis, including principal component analysis (PCA) and supervised orthogonal signal correction partial least-squares discriminant analysis (OSC-PLS-DA), were performed to evaluate variability among samples and between sample classes. Initially, unsupervised PCA was applied to reduce the dimensionality of imported ${ }^{1} \mathrm{H}-\mathrm{NMR}$ data by transforming to new latent variables, namely, principal components, to summarize the features of the data. Moreover, the supervised OSC-PLS-DA technique can eliminate irrelevant effects and maximize the distinction of intergroup differences. The OSC was applied prior to PLS-DA to filter out unrelated variables that do not contribute to class discrimination to minimize the influence of unrelated signals.

Repeated two-fold cross-validation and permutation test (2000 times) was conducted to evaluate the validation of the OSC-PLS-DA model. The parameters for the explained variation, $R^{2}$, and the predictive capability, $Q^{2}$, indicated the excellence of the constructed models [26]. Color-coded loading plots were constructed to demonstrate which variables are responsible for group separation. The fold-change values of metabolites were highlighted by using color-code in colored tables as well as their $p$-values adjusted by the Benjamini-Hochberg method [27].

Univariate analysis was performed using the parametric Student's $t$-test and nonparametric Mann-Whitney test [28] to estimate significant differences in crucial metabolites. The fold-change values of the identified metabolites and their associated $p$-values between groups were calculated. And then the obtained $p$-values were corrected using the Benjamini-Hochberg method to control the false discovery rate in multiple comparisons.

\section{Statistical analysis}

All the data were presented as means \pm standard deviation or averages and all experiments were conducted 
independently in triplicate. Analysis of variance (ANOVA) with Dunnett test was performed through SPSS version 17.0 (SPSS Inc., Chicago, IL, USA) software. Statistical significance was determined at $p<0.05$.

\section{Results}

\section{Elucidation of 3-CT}

The spectral data of 3-CT were as follows: ESI-MS, $\mathrm{m} / \mathrm{z}$ $739.09[\mathrm{M}-\mathrm{H}]^{-} .{ }^{1} \mathrm{H}-\mathrm{NMR}\left(500 \mathrm{MHz}, \mathrm{CD}_{3} \mathrm{OD}\right) \delta: 7.96(2 \mathrm{H}$, d, $\left.J=8.8 \mathrm{~Hz}, \mathrm{H}-2^{\prime}, 6^{\prime}\right), 7.73\left(1 \mathrm{H}, \mathrm{d}, J=15.9 \mathrm{~Hz}, \mathrm{H}-\gamma^{\prime \prime}\right), 7.49$ $(2 \mathrm{H}, \mathrm{d}, J=8.6 \mathrm{~Hz}, \mathrm{H}-2$ "', 6"'), $7.41(1 \mathrm{H}, \mathrm{d}, J=15.9 \mathrm{~Hz}, \mathrm{H}-$ $\left.\gamma^{\prime \prime \prime}\right), 7.30\left(2 \mathrm{H}, \mathrm{d}, J=8.6 \mathrm{~Hz}, \mathrm{H}-2^{\prime \prime \prime}, 6^{\prime \prime \prime}\right), 6.86(2 \mathrm{H}, \mathrm{d}, J=8.6$ Hz, H-3"', 5"'), $6.81\left(2 \mathrm{H}, \mathrm{d}, J=8.6 \mathrm{~Hz}, \mathrm{H}-3^{\prime \prime \prime}, 5^{\prime \prime \prime}\right), 6.80$ $\left(2 \mathrm{H}, \mathrm{d}, J=8.2 \mathrm{~Hz}, \mathrm{H}-3^{\prime}, 5^{\prime}\right), 6.49\left(1 \mathrm{H}, J=15.9 \mathrm{~Hz}, \mathrm{H}-\beta^{\prime \prime}\right)$, $6.24(1 \mathrm{H}, \mathrm{s}, \mathrm{H}-8), 6.09\left(1 \mathrm{H}, J=15.9 \mathrm{~Hz}, \mathrm{H}-\beta^{\prime \prime \prime}\right), 6.04(1 \mathrm{H}, J$ $=1.7 \mathrm{~Hz}, \mathrm{H}-6), 5.68(1 \mathrm{H}, J=8.0 \mathrm{~Hz}, \mathrm{H}-1$ "), $5.12(1 \mathrm{H}, \mathrm{t}, J=$ $\left.9.2 \mathrm{~Hz}, \mathrm{H}-3^{\prime \prime}\right), 4.39\left(1 \mathrm{H}, J=11.5 \mathrm{~Hz}, \mathrm{H}_{\mathrm{a}}-6^{\prime \prime}\right), 4.24(1 \mathrm{H}, \mathrm{dd}$, $\left.J=11.5,6.6 \mathrm{~Hz}, \mathrm{H}_{\mathrm{b}}-6^{\prime \prime}\right), 3.74\left(1 \mathrm{H}, \mathrm{m}, \mathrm{H}-4{ }^{\prime \prime}\right), 3.64(1 \mathrm{H}, \mathrm{m}$, H-5"), 3.47 (1H, m, H-2"). ${ }^{13} \mathrm{C}-\mathrm{NMR}\left(125 \mathrm{MHz}, \mathrm{CD}_{3} \mathrm{OD}\right)$

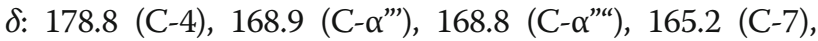
162.5 (C-5), 161.0 (C-4"'), 160.9 (C-4"'), 160.8 (C-4'), 158.8 (C-2), 158.0 (C-9), 147.1 (C- $\left.\gamma^{\prime \prime}\right), 146.4\left(\mathrm{C}-\gamma^{\prime \prime \prime \prime}\right), 134.4(\mathrm{C}-3)$, 132.1 (C-2', 6'), 131.2 (C-2"“" 6"“), 131.1 (C-2”, 6"'), 127.2 (C-1"'), 126.9 (C-1"“), 122.8 (C-1'), 116.7 (C-3"', 5"'“), 116.6 (C-3"', 5"'), 116.0 (C-3', 5'), 115.2 (C- $\beta^{\prime \prime \prime)}, 114.6$ (C- $\left.\beta^{\prime \prime \prime}\right)$, 105.7 (C-10), 100.4 (C-1"), 99.7 (C-6), 94.7 (C-8), 75.9 (C3"), 75.5 (C-5"), 75.6 (C-4"), 71.8 (C-2"), 64.4 (C-6"). All spectral data were in agreement with a report [21]. So it was identified as 3-cinnamoyltribuloside, which was isolated from $C$. nitidissima Chi flowers for the first time (Fig. 1a).

\section{Effects of 3-CT on cell viability in RAW 264.7 cells}

The potential effects of 3-CT on cell viability in RAW 264.7 cells were analyzed by the MTT assay after incubating cells for $24 \mathrm{~h}$ without LPS. As shown in Fig. 1b, when the concentrations of 3-CT were $0.625-10 \mu \mathrm{M}$, RAW 264.7 cells viability were not decreased within 24 $\mathrm{h}$, and at the concentrations of $20 \mu \mathrm{M}$ and $40 \mu \mathrm{M}, 3-\mathrm{CT}$ could markedly $(p<0.001)$ suppress the RAW 264.7 cells viability. So 3-CT had no cytotoxicity on RAW 264.7 cells at the concentrations of $0.625-10 \mu \mathrm{M}$.

\section{Effects of 3-CT on NO production in LPS-activated RAW 264.7 cells}

In this study, NO production was measured in the culture medium to determine the anti-inflammatory activity of 3-CT. LPS-activated RAW 264.7 cells were treated with 3-CT at the concentrations of $0.3125-10 \mu \mathrm{M}$. As shown in Fig. 1c, 3-CT showed inhibitory effects on the $\mathrm{NO}$ production at all tested concentrations, especially at $10 \mu \mathrm{M}$, the inhibition of NO production was $98.57 \%$. And even at the concentration $0.3125 \mu \mathrm{M}$, the inhibition of NO production was $15.87 \%$, which showed that the
NO production was significantly $(p<0.01)$ inhibited compared with the LPS-treated group (Fig. 1c).

Furthermore, we investigated the inhibitory activity of 3-CT on the LPS-activated iNOS mRNA expression in RAW 264.7 cells. As shown in Fig. 1d, compared with the control, the expression of iNOS mRNA was significantly $(p<0.001)$ increased when cells were stimulated by LPS. In contrast, treatment of 3-CT at the concentrations of $0.625-10 \mu \mathrm{M}$ all inhibited the mRNA expression of iNOS, with the strongest inhibitory effect at the concentration of $10 \mu \mathrm{M}$.

\section{Effects of 3-CT on the production of inflammatory cytokines}

Firstly, we investigated whether 3-CT could affect the mRNA expression of TNF- $\alpha$, IL- $1 \beta$, and IL- 6 , and the results were shown in Fig. 2a-c. At the concentrations of 0.625-10 $\mu \mathrm{M}, 3-\mathrm{CT}$ could inhibit the mRNA expression of TNF- $\alpha$ (Fig. 2a) compared with the LPS group. However, only at higher concentrations $(2.5 \mu \mathrm{M}, 5 \mu \mathrm{M}$, and $10 \mu \mathrm{M})$, did 3-CT suppress the mRNA expression of IL$1 \beta$ (Fig. 2b) and display little effect on IL-1 $\beta$ expression at lower concentrations $(0.625 \mu \mathrm{M}$ and $1.25 \mu \mathrm{M})$. Similarly, at the concentrations of $0.625 \mu \mathrm{M}, 1.25 \mu \mathrm{M}$, and $2.5 \mu \mathrm{M}, 3-\mathrm{CT}$ had no significant effects on the mRNA expression of IL-6, whereas, at the concentrations of 5 $\mu \mathrm{M}$ and $10 \mu \mathrm{M}, 3-\mathrm{CT}$ could significantly $(p<0.001)$ inhibit the mRNA expression of IL-6 (Fig. 2c).

Secondly, we measured the release of TNF- $\alpha$, IL-1 $\beta$, and IL- 6 in the culture medium by ELISA Kit. As shown in Fig. 2d-f, at the concentrations of $0.625-10 \mu \mathrm{M}, 3-\mathrm{CT}$ had remarkable inhibitory effects on TNF- $\alpha$, IL-1 $\beta$, and IL-6, respectively. Especially at $10 \mu \mathrm{M} 3-\mathrm{CT}$, the inhibition of the release of all of the three inflammatory cytokines was strongest in LPS-activated RAW 264.7 cells, which was similar to the results of their mRNA expressions.

\section{Metabolite assignment and multivariate data analysis} Representative $500 \mathrm{MHz}$ CPMG ${ }^{1} \mathrm{H}-\mathrm{NMR}$ spectra obtained from Con, LPS, HD, MD, and LD groups were shown in Fig. 3. From these spectrums, 35 metabolites identified and their detailed information is shown in Table 2, including their fold change value and $p$-values. The STOCSY technique was used to identify the correlation between spectral resonances of interest to assist the assignment of metabolites, such as lactate, dimethylamine, tyramine, and formate (Fig. S1). PCA score plot showed a clear separation between LPS-alone and 3-CT treated groups and doses groups overlapped with each other (Fig. S2). The supervised OSC-PLS-DA was then performed to reveal the significant changed metabolic among the five groups. The OSC-PLS-DA score plot (Fig. 4a) displays a clear separation between the control 


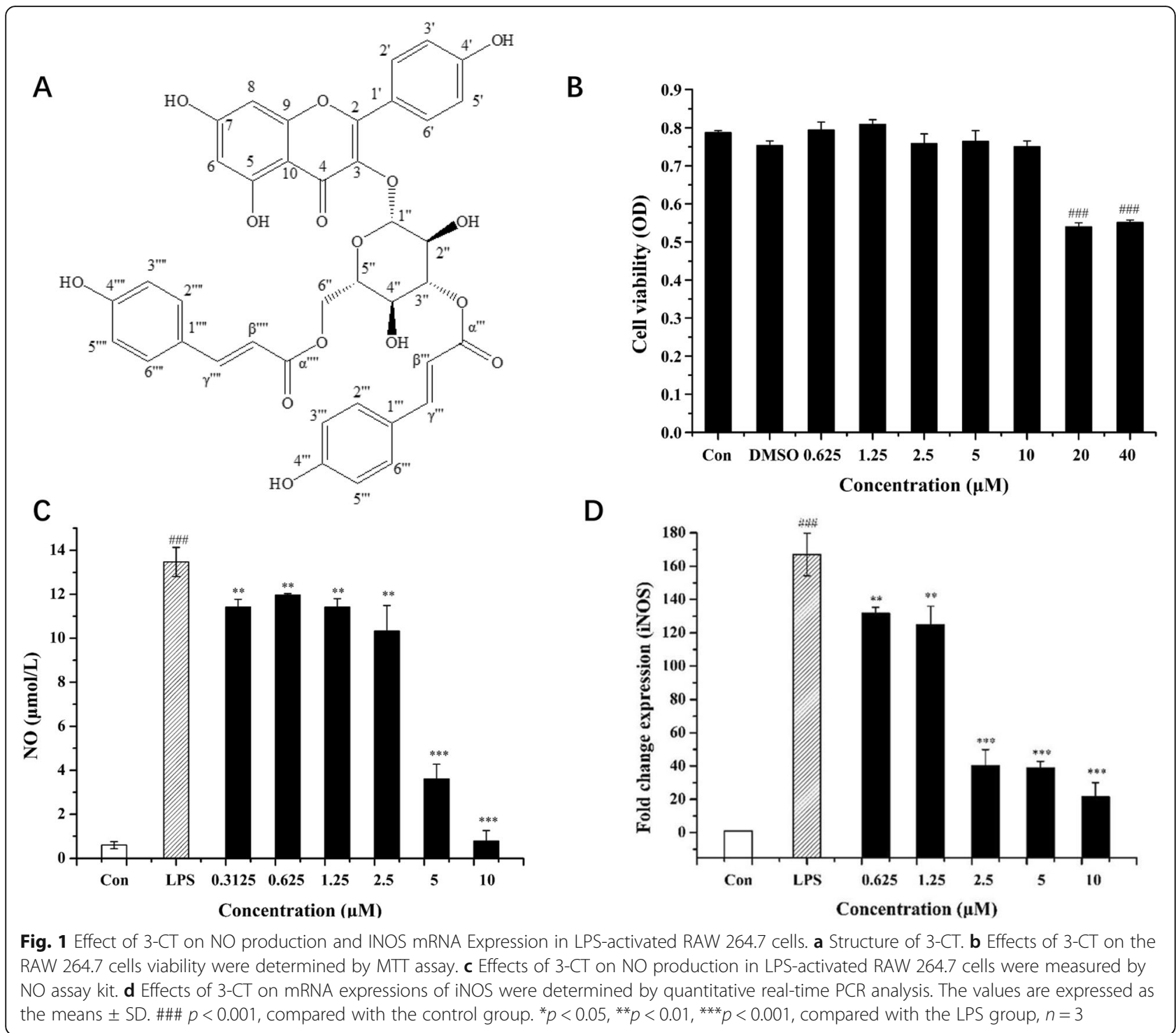

group and the LPS group, and similarly LD, MD groups showed significant discrimination with the LPS group. The metabolites responsible for the significant discrimination among these groups were demonstrated in S-plot (Fig. 4d) and the color-coded loading plots (Fig. 4b, c).

The major metabolites partly representing disease status were selected to evaluate the anti-inflammatory effects of 3CT. As shown in Table 2, the metabolites were quantified and illustrated, the LPS group had higher levels of alanine, creatine, glycine than the control group, but their levels were obviously reduced after 3 -CT treatment. Moreover, relative to the control group, the levels of ethanol, pyroglutamate, sarcosine, choline, taurine, glucose, tyramine, phenylalanine were significantly declined in the LPS group. Noteworthy, 3-CT treatment markedly increased these metabolites in RAW 264.7 cells. However, other metabolites did not show a significant recovery trend.

\section{Discussion}

In this study, 3-CT was isolated from $C$. nitidissima Chi flowers firstly, and its potent anti-inflammatory activity was evaluated in LPS-activated RAW 264.7 cells. 3-CT exhibited significant anti-inflammatory activity by inhibiting the production of inflammatory factors and mediators in LPS-activated RAW 264.7 cells. In addition, the ${ }^{1} \mathrm{H}$-NMR-based metabolomics approach combined with multivariate statistical analysis was applied to examine the metabolic responses to 3-CT treatment in LPS-activated RAW 264.7 cells. The significantly changed levels of metabolites induced by LPS in RAW 264.7 cells, such as the increase of levels of alanine, creatine, glycine and the decrease of the levels of ethanol, pyroglutamate, sarcosine, choline, taurine, glucose, tyramine, phenylalanine, were reversed after 3- CT treatment, suggesting a good balance effect of 


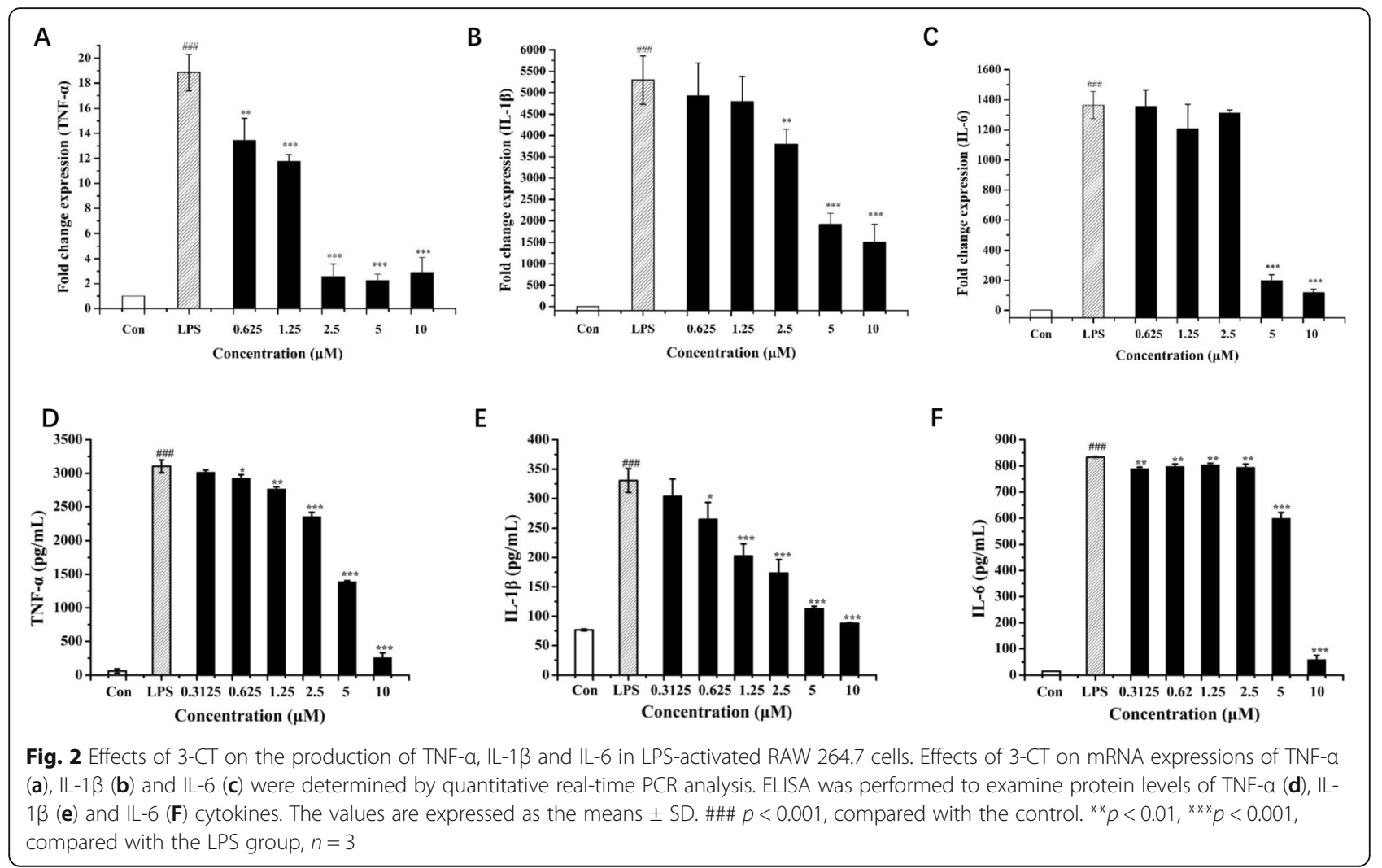

3-CT against LPS induced metabolic disorders in RAW 264.7 cells. Furthermore, the potential metabolic mechanism of the anti-inflammatory activity of 3-CT was preliminarily clarified base on significant changes in many endogenous metabolites, which are related to the cholinergic anti-inflammatory pathway, oxidative stress, energy metabolism, and amino acids metabolism in LPS-activated RAW 264.7 cells. Based on these findings, perturbed metabolic pathways were proposed (Fig. 5).

\section{Anti-inflammation}

$\mathrm{NO}$ plays a central role in diverse inflammatory and excessive NO could trigger deleterious consequences such as chronic inflammation, carcinogenesis, and sepsis $[7,29]$. And previous studies had shown that NO
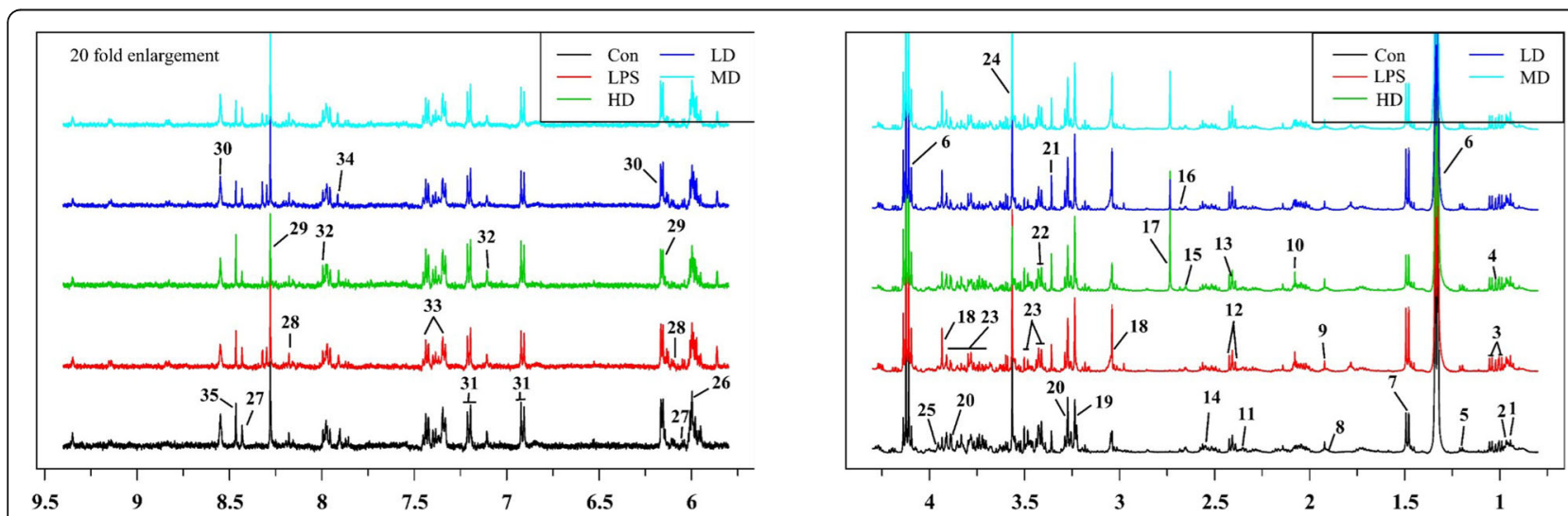

Fig. 3 Typical $500 \mathrm{MHz}{ }^{1} \mathrm{H}-\mathrm{NMR}$ spectra of RAW 264.7 cells with the metabolites labeled. Metabolites:1, 2-Aminobutyrate; 2, Leucine; 3, Valine; 4, Isoleucine; 5, Ethanol; 6, Lactate; 7, Alanine; 8, Lysine; 9, Acetate; 10, Homoserine; 11, Glutamate; 12, Pyroglutamat; 13, Succinate; 14, Glutathione; 15, 5, 6-Dihydrouracil; 16, Sarcosine; 17, Dimethylamine; 18, Creatine; 19, Choline; 20, Betaine; 21, Methanol; 22, Taurine; 23, Glucose; 24, Glycine; 25, Serine; 26, Cytosine; 27, NAD ${ }^{+}$28, NADP ${ }^{+}$; 29, AMP; 30, ATP; 31, Tyramine; 32, Histamine; 33, Phenylalanine; 34, Histidine; 35, Formate 
Table 2 Metabolites in RAW 264.7 cells identified by ${ }^{1} \mathrm{H}-\mathrm{NMR}$ and their fold changes among groups and the associated $p$-values

\begin{tabular}{|c|c|c|c|c|c|c|c|c|c|}
\hline \multirow{2}{*}{ No. } & \multirow{2}{*}{ Metabolites } & \multicolumn{2}{|c|}{ LPS VS CON } & \multicolumn{2}{|c|}{ HD VS LPS } & \multicolumn{2}{|c|}{ MD VS LPS } & \multicolumn{2}{|c|}{ LD VS LPS } \\
\hline & & $\mathrm{Fc}^{\mathrm{a}}$ & $p$-value ${ }^{\mathrm{b}}$ & $\mathrm{Fc}^{\mathrm{a}}$ & $p$-value ${ }^{\mathrm{b}}$ & $\mathrm{Fc}^{\mathrm{a}}$ & $p$-value ${ }^{\mathrm{b}}$ & $\mathrm{Fc}^{\mathrm{a}}$ & $p$-value ${ }^{\mathrm{b}}$ \\
\hline 1 & 2-Aminobutyrate & 0.88 & & 0.97 & & 1.13 & & 0.91 & \\
\hline 2 & Leucine & 1.07 & & 0.92 & & 0.97 & & 0.92 & \\
\hline 3 & Valine & 0.97 & & 1.04 & & 0.99 & & 0.98 & \\
\hline 4 & Isoleucine & 1.06 & & 1 & & 1 & & 0.99 & \\
\hline 5 & Ethanol & 0.69 & $* *$ & 1.46 & $* *$ & 1.14 & & 1.41 & $*$ \\
\hline 6 & Lactate & 1.33 & $* *$ & 1.02 & & 1.08 & & 1.1 & \\
\hline 7 & Alanine & 1.3 & $* *$ & 0.61 & $* * *$ & 0.75 & $* *$ & 0.98 & \\
\hline 8 & Lysine & 0.91 & & 1.06 & & 0.85 & $*$ & 0.81 & $*$ \\
\hline 9 & Acetate & 0.82 & $*$ & 1.16 & & 0.87 & & 0.81 & $*$ \\
\hline 10 & Homoserine & 0.56 & $* * *$ & 1.12 & & 0.89 & $*$ & 1 & \\
\hline 11 & Glutamate & 0.91 & & 0.83 & $* *$ & 0.76 & $* *$ & 0.86 & $*$ \\
\hline 12 & Pyroglutamate & 0.86 & $* *$ & 1.13 & $*$ & 1.09 & & 1.04 & \\
\hline 13 & Succinate & 1.03 & & 1.07 & & 1.1 & $*$ & 1.08 & $*$ \\
\hline 14 & Glutathione & 0.68 & $* *$ & 0.91 & $*$ & 0.94 & & 0.93 & \\
\hline 15 & 5, 6-Dihydrouracil & 0.69 & $* * *$ & 0.91 & & 0.79 & $* *$ & 0.8 & $* * *$ \\
\hline 16 & Sarcosine & 0.72 & $* * *$ & 1.27 & $* *$ & 0.82 & $* *$ & 0.82 & $*$ \\
\hline 17 & Dimethylamine & 1.07 & & 32.47 & $* * *$ & 19.59 & $* * *$ & 8.53 & $* * *$ \\
\hline 18 & Creatine & 2 & $* * *$ & 0.47 & $* *$ & 0.92 & & 0.97 & \\
\hline 19 & Choline & 0.33 & $* *$ & 1.39 & $* *$ & 0.66 & & 0.68 & \\
\hline 20 & Betaine & 0.87 & $* *$ & 0.84 & & 1.01 & & 0.98 & \\
\hline 21 & Methanol & 0.97 & & 1.25 & & 1.04 & & 1.12 & \\
\hline 22 & Taurine & 0.62 & $* * *$ & 1.05 & $*$ & 0.98 & & 0.9 & $*$ \\
\hline 23 & Glucose & 0.53 & $* * *$ & 1.36 & $* * *$ & 0.93 & & 0.84 & \\
\hline 24 & Glycine & 1.12 & $*$ & 0.38 & $* * *$ & 0.76 & $* *$ & 0.98 & \\
\hline 25 & Serine & 0.78 & & 0.85 & & 0.91 & & 1.05 & \\
\hline 26 & Cytosine & 0.63 & $* *$ & 1.05 & & 0.86 & & 0.86 & \\
\hline 27 & $\mathrm{NAD}^{+}$ & 0.88 & & 0.99 & & 0.9 & & 0.82 & \\
\hline 28 & $\mathrm{NADP}^{+}$ & 0.85 & & 0.83 & $*$ & 0.83 & & 0.88 & \\
\hline 29 & AMP & 0.72 & & 0.94 & & 0.91 & & 0.94 & \\
\hline 30 & ATP & 0.65 & & 0.99 & & 1.02 & & 1.03 & \\
\hline 31 & Tyramine & 0.79 & $* *$ & 1.26 & $* *$ & 0.9 & & 0.87 & \\
\hline 32 & Histamine & 1.02 & & 1 & & 0.81 & $*$ & 0.82 & $*$ \\
\hline 33 & Phenylalanine & 0.67 & $* *$ & 1.41 & $* *$ & 0.94 & & 0.96 & \\
\hline 34 & Histidine & 0.38 & $* *$ & 1.18 & & 0.78 & & 1.06 & \\
\hline 35 & Formate & 0.77 & & 1.38 & & 0.69 & $*$ & 0.8 & \\
\hline
\end{tabular}

a Color coded according to the fold change value, red represents increased and blue represents decreased concentrations of metabolites.

Metabolite color bar

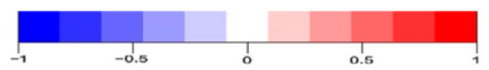

${ }^{\mathrm{b}} p$-values corrected by BH (Benjamini Hochberg) methods were calculated based on a parametric Student's $t$-test or a nonparametric Mann-Whitney test (dependent on the conformity to normal distribution). ${ }^{*} p<0.05, * * p<0.01, * * * p<0.001$. 


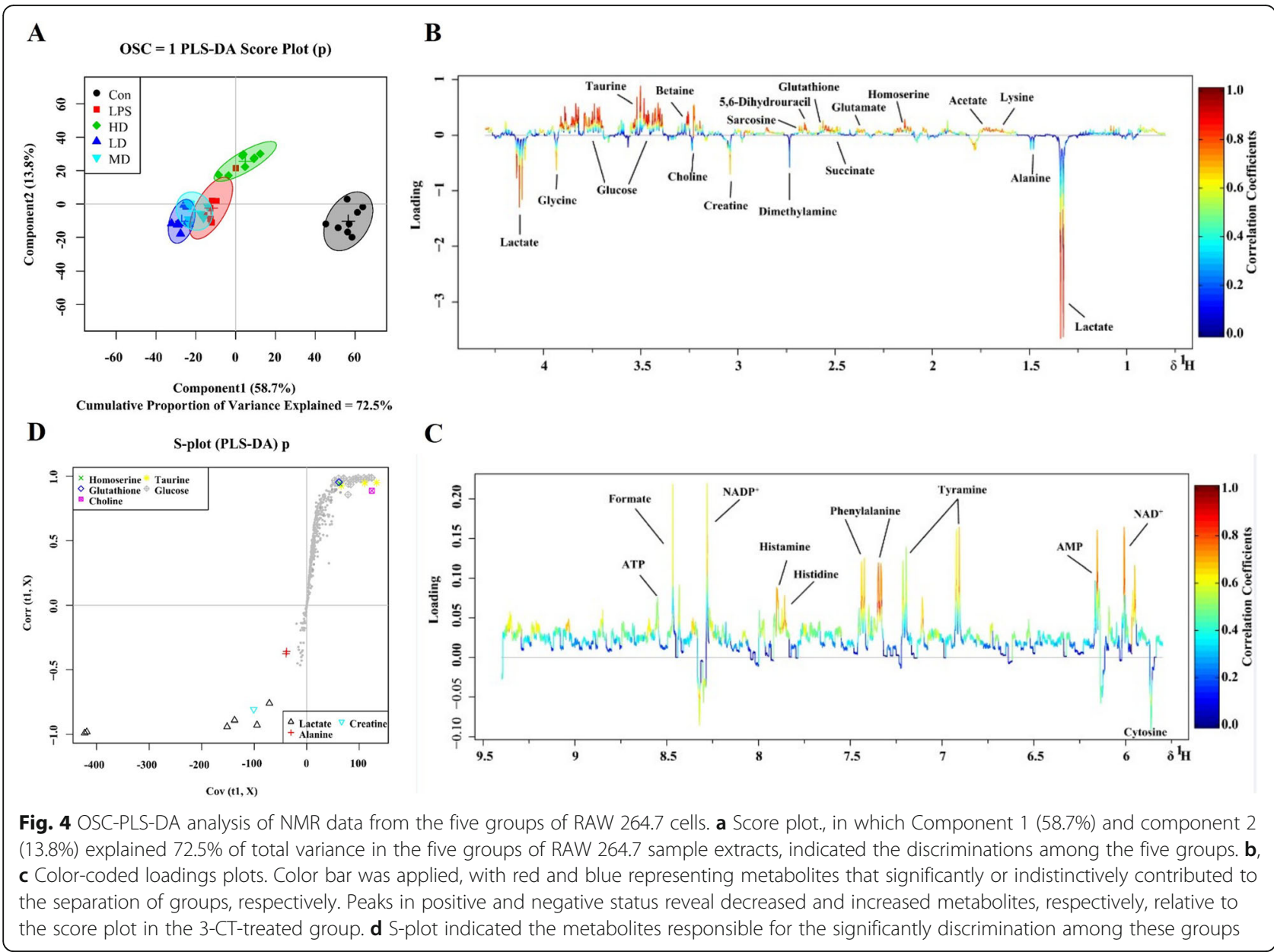

is generated from $\mathrm{L}$-arginine by the enzymatic action of three highly homologous nitric oxide synthase (NOS): endothelial (eNOS), neuronal (nNOS), and inducible (iNOS). And each isoform had separate functions. Activated macrophages transcriptionally express iNOS, which is responsible for the prolonged and excessive production of NO. So some compounds might suppress the synthesis of iNOS protein or inhibit iNOS activity to decrease the $\mathrm{NO}$ production [30,31]. In this study, we found that NO production and iNOS mRNA expression was inhibited in LPS-activated RAW264.7 cells after 3-CT treatment. So the results indicated that $3-\mathrm{CT}$ could inhibit the NO production by suppression of the (over-)expression of iNOS to show excellent anti-inflammatory activity.

Macrophages, stimulated by LPS, could release a series of inflammatory cytokines, including TNF- $\alpha$, IL- $1 \beta$, and IL- 6 , all of which were involved in a variety of immunological reactions [32]. So the inhibitory effects of compounds on inflammatory cytokines in LPS-activated RAW 264.7 cells were always used to evaluate the activity of antiinflammatory agents $[1,33]$. Our results showed that, after 3-CT $(10 \mu \mathrm{M})$ treatment, the expression of a series of inflammatory cytokines, including TNF- $\alpha$, IL-1 $\beta$, and IL-6, both at mRNA level and protein level, were significantly decreased. Based on these findings, we infered that 3-CT had inhibitory effects on the production of inflammatory cytokines (TNF- $\alpha$, IL-1 $\beta$, and IL-6), by interfering the mRNA expression and the release of inflammatory cytokines.

\section{Cholinergic anti-inflammatory pathway}

The cholinergic anti-inflammatory pathway could be stimulated by electrical [34] or medicine methods, like nicotine, the drug AR-R17779 $[35,36]$ to regulate the inflammatory response and reduce the inflammatory damage. It could suppress systemic levels of TNF and other pro-inflammatory cytokines. And choline was an important component of the cholinergic anti-inflammatory pathway, which might reflect the anti-inflammatory effects of some medicines via a change in the level of choline [37-39]. Ma et al. found that saikosaponins which had anti-inflammatory activity could mitigate the imbalance of serum level of choline in inflammation mice model induced by formalin [40]. Similar results were also found in our study. As shown in Table 2, in the LPS group, choline markedly decreased compared with the control group, whereas in the HD group, choline 


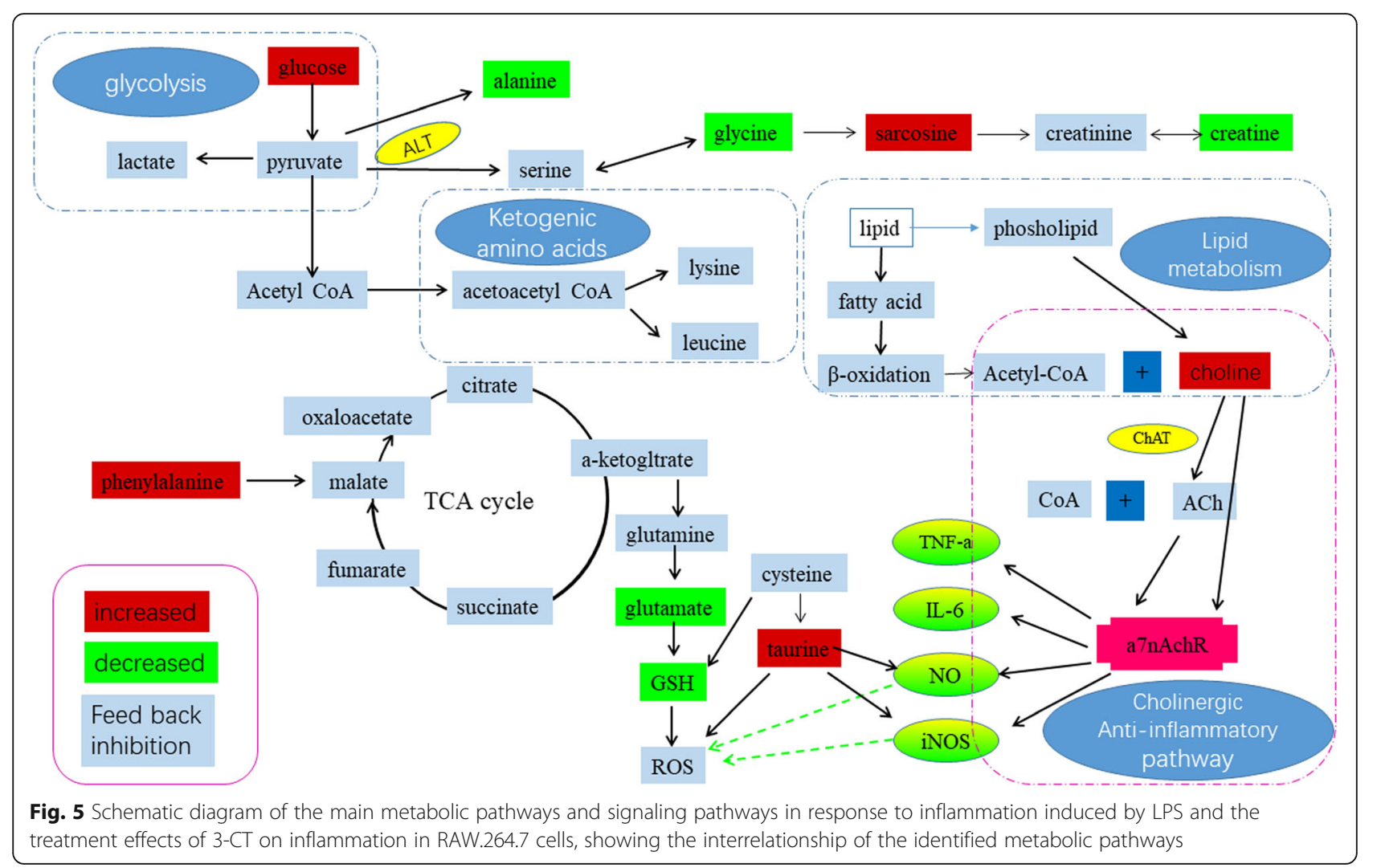

significantly increased compared with the LPS group. In addition, it was reported that choline treatment stimulates the synthesis and release of acetylcholine (Ach) [41] and Ach could reduce the expression of TNF- $\alpha$, IL- $1 \beta$, IL- 6 in the cholinergic anti-inflammatory pathway [42]. In this study, 3-CT enhances the choline level in LPS-activated RAW 264.7 cells, which facilitates the synthesis of Ach. Therefore, the result indicated that 3-CT shows the anti-inflammatory activity, possibly, attributed to its regulation of the cholinergic anti-inflammatory pathway.

\section{Oxidative stress}

Oxidative stress could be considered as an imbalance between the production of reactive oxygen species (ROS) and the ability of the organism's natural protective mechanisms to cope with these reactive compounds and prevent adverse effects, in which antioxidative enzymes played a key regulatory role to keep a certain stats of homeostasis [28]. Glutathione (GSH) redox system was a primary defense mechanism, which was important for maintaining the redox balance [43]. Compared with the LPS group, glutathione was significantly decreasing in the HD group, and glutamate remarkably decreased in HD, MD, and LD groups. The changes with treatment with 3-CT indicated that glutamate and glutathione were excessively consumed to balance the oxidative stress after being activated by LPS in RAW 264.7 cells. And this result revealed that 3-CT could not restore equilibrium to the GSH redox system and even slightly exacerbate the imbalance.

In inflammation, the excessive formation of NO could react with ROS to generate peroxynitrite that is implicated in oxidative damage [44], so the inhibitory effects of 3-CT on NO production could decrease the oxidative damage in LPS-activated RAW 264.7 cells.

Cell membranes are vulnerable to oxidative damage caused by unsaturated fatty acids [45]. Whereas, choline and phosphocholine are essential for maintaining the structural integrity of cell membranes. Compared with the control group, choline remarkably decreased in the LPS group, and in the HD group, choline significantly increased compared with the LPS group. The results indicated that when activated by LPS, choline was consumed to defend against the oxidative damage in RAW 264.7 cells, and by the treatment with $3-\mathrm{CT}$, the consumption of choline was decreased which might result from the reduction of the oxidative stress in RAW 264.7 cells. As an antioxidant, taurine showed protective effects against oxidative stress $[46,47]$. Similar to choline, compared with the control group, taurine remarkably decreased in the LPS group, and in the HD group, taurine significantly increased compared with the LPS group. So the changes of taurine also showed that 3-CT 
could decrease the oxidative damage in LPS-activated RAW 264.7 cells. And similar results had also been found that flavonoids from Glycyrrhiza exhibited antiinflammatory effects on treating arthritis in mice while attenuated the decrease of taurine level in urine [48].

Taken together, 3-CT had an effect on the levels of metabolites (glutathione, NO, choline, taurine) related to oxidative stress in RAW 264.7 cells. And it indicated the anti-inflammatory activity of 3-CT might be related to these effects.

\section{Energy metabolism}

In inflammation, more energy must be generated for the accelerated metabolism due to the acute inflammatory insult $[39,49]$. In this study, in the LPS group, glucose remarkably decreased compared with the control group, so it showed that large amounts of glucose were consumed to produce energy after RAW 264.7 cells were activated by LPS. But by the treatment with $3-C T$, the level of glucose significantly increased in the HD group compared with the LPS group. This result is consistent with those of previous studies. Yao et al. detected a slight increase in plasm glucose levels in mice after volatile oil treatment relative to the model group [50]. Therefore it could speculate that 3-CT showed the antiinflammatory effect in LPS-activated RAW 264.7 cells, which resulted in the decrease of energy demand, then the consumption of glucose remarkably decreased. However, it was notable that the level of ATP did not increase, even decreased (no statistic significance), when glucose was consumed to produce energy after RAW 264.7 cells were activated by LPS. Based on this result, it could speculate that the energy produced from glucose could not satisfy the increasing energy demand.

When the tricarboxylic acid cycle was inhibited, other sources were called for the enhancement energy supply, such as anoxic respiration, glycolysis, where pyruvate could generate energy by being metabolized to lactate and alanine [39, 51]. Compared with the control group, lactate and alanine both significantly increased in the LPS group, and in HD and MD groups, alanine remarkably decreased compared with the LPS group. However, anaerobic respiration is not as effective as aerobic respiration in energy production, which could not produce enough energy to meet the energy requirements of cells stimulated by LPS. This might be the reason why the level of ATP did not rise after 3-CT treatment and it also indicated 3-CT did not restore aerobic respiration to produce enough energy in LPS-activated RAW 264.7 cells.

So we could conclude that the energy metabolism of RAW 264.7 cells was disturbed after the induction by LPS. By the treatment with 3-CT, the energy metabolism in anaerobic respiration became balanced might due to its anti-inflammatory activity, which could reduce the energy demand of LPS-activated RAW 264.7 cells.

\section{Amino acids metabolism}

Phenylalanine was an essential amino acid and involved in the synthesis of many important functional proteins $[52,53]$. Compared with the control group, the level of phenylalanine remarkably decreased in the LPS group, which reflected the effects of LPS on muscle protein metabolism in RAW 264.7 cells. After treated by 3-CT, the level of phenylalanine significantly increased in the HD group compared with the LPS group. These results showed that 3-CT had the ability to balance phenylalanine metabolism in LPS-activated RAW 264.7 cells. Besides, as shown in Table 2, the levels of alanine, lysine, homoserine, sarcosine, glycine, and histidine all showed significant changes following the treatment with 3-CT. Amino acids play important roles both as basic substrates and as regulators in many metabolic pathways [54]. So it further concluded that 3-CT might show the anti-inflammatory activity through affecting amino acids metabolism in LPS-activated RAW 264.7 cells.

\section{Conclusions}

In this study, 3-CT was isolated from C. nitidissima Chi flowers for the first time exhibiting potent antiinflammatory activity in LPS-activated RAW 264.7 cells. To our best knowledge, it was the first time to report the anti-inflammatory activity of 3-CT. 3-CT could inhibit the NO production and mRNA expression of iNOS involved in LPS-activated RAW 264.7 cells. Furthermore, the results of mRNA expression and ELISA assay indicated that 3-CT also had the ability to inhibit the production of inflammatory cytokines, including TNF- $\alpha$, IL-1 $\beta$, and IL-6 in LPS-activated RAW 264.7 cells. The potential metabolic mechanism of the anti-inflammatory activity of 3-CT was explored by using ${ }^{1} \mathrm{H}-\mathrm{NMR}$ based metabolomics approach and 35 metabolites were identified via the CPMG ${ }^{1} \mathrm{H}$-NMR spectra. The significant change metabolites were further confirmed by using multivariate statistical analysis. Our results illustrated that 3-CT had effects on cholinergic anti-inflammatory pathway, oxidative stress, energy metabolism, and amino acids metabolism in LPS-activated RAW 264.7 cells.

\section{Supplementary information}

The online version contains supplementary material available at https://doi. org/10.1186/s12906-020-03115-y.

Additional file 1: Figure S1. Example of two-dimensional statistical total correlation spectroscopy (STOCSY) analysis of ${ }^{1} \mathrm{H}-\mathrm{NMR}$ spectrum RAW 264.7 extracts to facilitate the identification of metabolites. (A) 2D STOCSY subplots from 5.8 to 9.4 ppm for the assignments of formate and tyramine; (B) 2D STOCSY subplots from 0.8 to 4.3 ppm for the assignments of dimethylamine and lactate. 
Additional file 2: Figure S2. PCA scores plot for Con, LPS, HD, MD and LD groups.

Additional file 3: Figure S3. ${ }^{1} \mathrm{H}-\mathrm{NMR}$ spectra of 3-CT.

Additional file 4: Figure S4. ${ }^{13} \mathrm{C}-\mathrm{NMR}$ spectra of 3-CT.

Additional file 5: Table S1. The characteristic chemical shifts of metabolites in ${ }^{1} \mathrm{H}$-NMR spectra.

\section{Abbreviations}

3-CT: 3-cinnamoyltribuloside; LPS: Lipopolysaccharide; TNF-a: Tumor necrosis factor-a; IL-1ß: Interleukin-1ß; IL-6: Interleukin-6; NO: Nitric oxide; MTT: (3-4,5dimethylthiazol-2-yl)-2,5-diphenyl tetrazolium bromide; DMSO: Dimethyl sulfoxide; TSP: Sodium 3-(trimethylsilyl)-propionic acid; DMEM: Dulbecco's modified eagle medium; FBS: Foetal bovine serum; PCA: Principal component analysis; OSC-PLS-DA: Supervised orthogonal signal correction partial least-squares discriminant analysis; STOCSY: Statistical total correlation spectroscopy

\section{Acknowledgments}

We are thankful to senior engineer Yang Jizhu for the plant identification and authorization. We are also grateful to Dr. Xu Yuan for his kind gift (A murine macrophage cell line RAW 264.7) from Nanjing University of Chinese Medicine (Nanjing, China)

\section{Authors' contributions}

Conception and design of study: JW, AJ. Acquisition of data: ZW, YG, RY, JL. Analysis and interpretation of data: $Z W, Y G, R Y, J L$. Drafting the manuscript: $Z W, Y G, R Y$. All authors read and approved the final manuscript.

\section{Funding}

This work was supported by grants from the National Key Research and Development Program of China (2017YFD0201401), National Natural Science Foundation of China (41766006), and Six Talent Peaks Project in Jiangsu Province. These funders had no role in study design, conduct of experiments, data analysis, decision to publish or preparation of the manuscript.

\section{Availability of data and materials}

The datasets used and/or analyzed during the current study available from the corresponding author on reasonable request.

\section{Ethics approval and consent to participate}

Not applicable.

\section{Consent for publication}

Not applicable.

\section{Competing interests}

The authors declare no competing interest.

\section{Author details}

${ }^{1}$ School of Environmental and Biological Engineering, Nanjing University of Science and Technology, Nanjing 210094, China. ${ }^{2}$ School of Life and Pharmaceutical Sciences, Key Laboratory of Tropical Biological Resources of Ministry Education, Hainan University, Haikou 570228, China. ${ }^{3}$ Inspection and Pattern Evaluation Department, Suzhou Institute of Metrology, Suzhou 215000, China.

Received: 28 June 2020 Accepted: 9 October 2020

Published online: 02 November 2020

\section{References}

1. Wu J, Liu Z, Su J, Pan N, Song Q. Anti-inflammatory activity of 3ßhydroxycholest-5-en-7-one isolated from Hippocampus trimaculatus leach via inhibiting iNOS, TNF- $a$, and 1L-1 $\beta$ of LPS induced RAW 264.7 macrophage cells. Food Funct. 2017:8:788-95.

2. Mauriz JL, Collado PS, Veneroso C, Reiter RJ, González-Gallego J. A review of the molecular aspects of melatonin's anti-inflammatory actions: recent insights and new perspectives. J Pineal Res. 2013;54:1-14.
3. Iwalewa E, McGaw L, Naidoo V, Eloff J. Inflammation: the foundation of diseases and disorders. A review of phytomedicines of south African origin used to treat pain and inflammatory conditions. Afr J Biotechnol. 2007;6: 2868-85.

4. Wang $Y, X u Y$, Zhang P, Ruan W, Zhang L, Yuan S, et al. Smiglaside a ameliorates LPS-induced acute lung injury by modulating macrophage polarization via AMPK-PPARy pathway. Biochem Pharmacol. 2018;156: 385-95.

5. Kim J-W, Zhou Z, Yun H, Park S, Choi S-J, Lee S-H, et al. Cigarette smoking differentially regulates inflammatory responses in a mouse model of nonalcoholic steatohepatitis depending on exposure time point. Food Chem Toxicol. 2019;110930.

6. Kiemer AK, Müller C, Vollmar AM. Inhibition of LPS-induced nitric oxide and TNF-a production by a-lipoic acid in rat Kupffer cells and in RAW 264.7 murine macrophages. Immunol Cell Biol. 2002;80:550-7.

7. Zhang T-T, Wang M, Yang L, Jiang J-G, Zhao J-W, Zhu W. Flavonoid glycosides from Rubus chingii Hu fruits display anti-inflammatory activity through suppressing MAPKs activation in macrophages. J Funct Foods. 2015;18:235-43.

8. Shivraj Hariram N, Se WP. Optimized methods for in vitro and in vivo antiinflammatory assays and its applications in herbal and synthetic drug analysis. Mini-Rev Med Chem. 2013;13:95-100.

9. Sun Y, Liu J, Jiang $X$, Sun T, Liu L, Zhang $X$, et al. One-step synthesis of chiral Oxindole-type analogues with potent anti-inflammatory and analgesic activities. Sci Rep-UK. 2015;5:13699.

10. Zhou Z-L, Yang Y-X, Ding J, Li Y-C, Miao Z-H. Triptolide: structural modifications, structure-activity relationships, bioactivities, clinical development and mechanisms. Nat Prod Rep. 2012:29:457-75.

11. Zhang A, Sun $H$, Wang $X$. Recent advances in natural products from plants for treatment of liver diseases. Eur J Med Chem. 2013:63:570-7.

12. Toker G, Küpeli E, Memisoğlu M, Yesilada E. Flavonoids with antinociceptive and anti-inflammatory activities from the leaves of Tilia argentea (silver linden). J Ethnopharmacol. 2004;95:393-7.

13. Wang $Y$, Chen $P$, Tang $C$, Wang $Y$, Li Y, Zhang $H$. Antinociceptive and antiinflammatory activities of extract and two isolated flavonoids of Carthamus tinctorius L.J. Ethnopharmacol. 2014;151:944-50.

14. Chuang C-C, Mclntosh MK. Potential mechanisms by which polyphenol-rich grapes prevent obesity-mediated inflammation and metabolic diseases. Annu Rev Nutr. 2011:31:155-76.

15. Liu D, Cao G, Han L, Ye Y, SiMa Y, Ge W. Flavonoids from Radix Tetrastigmae inhibit TLR4/MD-2 mediated JNK and NF-KB pathway with anti-inflammatory properties. Cytokine. 2016;84:29-36.

16. Zhang H, Tsao R. Dietary polyphenols, oxidative stress and antioxidant and anti-inflammatory effects. Curr Opin Food Sci. 2016;8:33-42.

17. Yang R, Wang W-X, Chen H-J, He Z-C, Jia A-Q. The inhibition of advanced glycation end-products by five fractions and three main flavonoids from Camellia nitidissima chi flowers. J Food Drug Anal. 2018a;26:252-9.

18. Yang R, Guan Y, Zhou J, Sun B, Wang Z, Chen H, et al. Phytochemicals from Camellia nitidissima chi flowers reduce the Pyocyanin production and motility of Pseudomonas aeruginosa PAO1. Front Microbiol. 2018b;8:2640.

19. Yang $R$, Guan $Y$, Wang W, Chen $H$, He Z, Jia A-Q. Antioxidant capacity of phenolics in Camellia nitidissima chi flowers and their identification by HPLC triple TOF MS/MS. PLoS One. 2018c:13:e0195508.

20. Chen YY, Huang YL, Wen YX. Advance in study on chemical constituents and pharmacological action of Camellia chrysantha. Guangxi Trop Agric. 2009;1:14-6.

21. Christopher R, Nyandoro SS, Chacha M, de Koning CB. A new cinnamoylglycoflavonoid, antimycobacterial and antioxidant constituents from Heritiera littoralis leaf extracts. Nat Prod Res. 2014:28:351-8.

22. Bharitkar YP, Hazra A, Apoorva Poduri NS, Ash A, Maulik PR, Mondal NB. Isolation, structural elucidation and cytotoxicity evaluation of a new pentahydroxy-pimarane diterpenoid along with other chemical constituents from Aerva lanata. Nat Prod Res. 2015;29:253-61.

23. Oppong MB, Zhang B-Y, Fang S-M, Qiu F. Secondary metabolites from Sterculia lychnophora Hance (Pangdahai). Biochem Syst Ecol. 2020;92: 104125.

24. Deng A, Kang X, Zhang J, Yang Y, Yang S. Enhanced gelation of chitosan/ $\beta$ sodium glycerophosphate thermosensitive hydrogel with sodium bicarbonate and biocompatibility evaluated. Mater Sci. Eng C Mater Biol Appl. 2017;78:1147-54 
25. Xing Y-X, Li M-H, Tao L, Ruan L-Y, Hong W, Chen C, et al. Anti-Cancer effects of Emodin on HepG2 cells as revealed by $1 \mathrm{H}$ NMR based metabolic profiling. J Proteome Res. 2018;17:1943-52.

26. Li M, Wang J, Lu Z, Wei D, Yang M, Kong L. NMR-based metabolomics approach to study the toxicity of lambda-cyhalothrin to goldfish (Carassius auratus). Aquat Toxicol. 2014;146:82-92.

27. Liu Y, Chen T, Li M-H, Xu H-D, Jia A-Q, Zhang J-F, Wang J-S. 1 H NMR based metabolomics approach to study the toxic effects of dichlorvos on goldfish (Carassius auratus). Chemosphere. 2015;138:537-45.

28. Chen T, Sheng J, Fu Y, Li M, Wang J, Jia A-Q. 1H NMR-based global metabolic studies of Pseudomonas aeruginosa upon exposure of the quorum sensing inhibitor resveratrol. J Proteome Res. 2017;16:824-30.

29. Coulter JA, McCarthy HO, Xiang J, Roedl W, Wagner E, Robson T, et al. Nitric oxide-a novel therapeutic for cancer. Nitric Oxide. 2008;19:192-8.

30. Mattiello T, Fiore G, Brown ER, d'Ischia M, Palumbo A. Nitric oxide mediates the glutamate-dependent pathway for neurotransmission in Sepia officinalis Chromatophore organs. J Biol Chem. 2010;285:24154-63.

31. Singh G, Kaur A, Kaur J, Bhatti MS, Singh P, Bhatti R. Bergapten inhibits chemically induced nociceptive behavior and inflammation in mice by decreasing the expression of spinal PARP, iNOS, COX-2 and inflammatory cytokines. Inflammopharmacology. 2019;27:749-60.

32. Yoshimura A. Signal transduction of inflammatory cytokines and tumor development. Cancer Sci. 2006;97:439-47.

33. Peng L, Ai-lati A, Ji Z, Chen S, Mao J. Polyphenols extracted from huangjiu have anti-inflammatory activity in lipopolysaccharide stimulated RAW264.7 cells. RSC Adv. 2019;9:5295-301.

34. Pavlov VA, Tracey KJ. Controlling inflammation: the cholinergic antiinflammatory pathway. Biochem Soc T. 2006;34:1037-40.

35. Park J, Kang J-W, Lee S-M. Activation of the cholinergic anti-inflammatory pathway by nicotine attenuates hepatic ischemia/reperfusion injury via heme oxygenase-1 induction. Eur J Pharmacol. 2013;707:61-70.

36. Pohanka M, Snopkova S, Havlickova K, Bostik P, Sinkorova Z, Fusek J, et al. Macrophage-assisted inflammation and pharmacological regulation of the cholinergic anti-inflammatory pathway. Curr Med Chem. 2011;18:539-51.

37. Shaked I, Meerson A, Wolf Y, Avni R, Greenberg D, Gilboa-Geffen A, et al. MicroRNA-132 potentiates cholinergic anti-inflammatory signaling by targeting Acetylcholinesterase. Immunity. 2009;31:965-73.

38. Jeremias IC, Victorino VJ, Barbeiro HV, Kubo SA, Prado CM, Lima TM, et al. The role of acetylcholine in the inflammatory response in animals surviving Sepsis induced by Cecal ligation and puncture. Mol Neurobiol. 2016;53: 6635-43.

39. Xu D, LV Y, Wang J, Yang M, Kong L. Deciphering the mechanism of Huang-Lian-Jie-Du-decoction on the treatment of sepsis by formula decomposition and metabolomics: enhancement of cholinergic pathways and inhibition of HMGB-1/TLR4/NF-KB signaling. Pharmacol Res. 2017;121: 94-113.

40. Ma Y, Bao Y, Wang S, Li T, Chang X, Yang G, et al. Anti-inflammation effects and potential mechanism of Saikosaponins by regulating Nicotinate and Nicotinamide metabolism and Arachidonic acid metabolism. Inflammation. 2016;39:1453-61.

41. IIcol YO, Gurun MS, Taga Y, Ulus $H_{H}$. Choline increases serum insulin in rat when injected intraperitoneally and augments basal and stimulated aceylcholine release from the rat minced pancreas in vitro. Eur J Biochem. 2003;270:991-9.

42. Borovikova LV, Ivanova S, Zhang M, Yang H, Botchkina Gl, Watkins LR, et al, Vagus nerve stimulation attenuates the systemic inflammatory response to endotoxin. Nature. 2000:405:458-62.

43. Chen T, Liu Y, Li M-H, Xu H-D, Sheng J-Y, Zhang L, et al. Integrated $1 \mathrm{H}$ NMR-based metabolomics analysis of earthworm responses to sub-lethal $\mathrm{Pb}$ exposure. Environ Chem. 2016;13:792-803.

44. Griendling Kathy K, FitzGerald GA. Oxidative stress and cardiovascular injury: part I: basic mechanisms and in vivo monitoring of ROS. Circulation. 2003; 108:1912-6.

45. Schmidley JW. Free radicals in central nervous system ischemia. Stroke. 1990;21:1086-90.

46. Hagar $\mathrm{HH}$. The protective effect of taurine against cyclosporine A-induced oxidative stress and hepatotoxicity in rats. Toxicol Lett. 2004;151:335-43.

47. Ghosh S, Chowdhury S, Das AK, Sil PC. Taurine ameliorates oxidative stress induced inflammation and ER stress mediated testicular damage in STZinduced diabetic Wistar rats. Food Chem Toxicol. 2019;124:64-80.
48. Wei M, Ma Y, Liu Y, Zhou Y, Men L, Yue K, et al. Urinary metabolomics study on the anti-inflammation effects of flavonoids obtained from Glycyrrhiza. J Chromatogr B. 2018;1086:1-10.

49. Mervyn Singer MB, MD, FRCP. Mitochondrial function in sepsis: Acute phase versus multiple organ failure. Crit Care Med. 2007;35(Suppl 9):441-8.

50. Yao W, Zhang L, Hua Y, Ji P, Li P, Li J, Zhong L, Zhao H, Wei Y. The investigation of anti-inflammatory activity of volatile oil of Angelica sinensis by plasma metabolomics approach. Int Immunopharmacol. 2015;29:269-77.

51. Casserly B, Phillips GS, Schorr C, Dellinger RP, Townsend SR, Osborn TM, et al. Lactate measurements in Sepsis-induced tissue Hypoperfusion: results from the surviving Sepsis campaign database*. Crit Care Med. 2015:43:567-73.

52. Rosengren E, Åman P, Thelin S, Hansson C, Ahlfors S, Björk P, Jacobsson L, Rorsman $\mathrm{H}$. The macrophage migration inhibitory factor MIF is a phenylpyruvate tautomerase. FEBS Lett. 1997;417:85-8.

53. Keidar S, Strizevsky A, Raz A, Gamliel-Lazarovich A. ACE2 activity is increased in monocyte-derived macrophages from prehypertensive subjects. Nephrol Dial Transplant. 2007;22:597-601.

54. Pearce Erika L, Pearce EJ. Metabolic pathways in immune cell activation and quiescence. Immunity. 2013;38:633-43.

\section{Publisher's Note}

Springer Nature remains neutral with regard to jurisdictional claims in published maps and institutional affiliations.
Ready to submit your research? Choose BMC and benefit from:

- fast, convenient online submission

- thorough peer review by experienced researchers in your field

- rapid publication on acceptance

- support for research data, including large and complex data types

- gold Open Access which fosters wider collaboration and increased citations

- maximum visibility for your research: over $100 \mathrm{M}$ website views per year

At BMC, research is always in progress.

Learn more biomedcentral.com/submissions 